\title{
Article \\ Machine Learning Approach to Predict Quality Parameters for Bacterial Consortium-Treated Hospital Wastewater and Phytotoxicity Assessment on Radish, Cauliflower, Hot Pepper, Rice and Wheat Crops
}

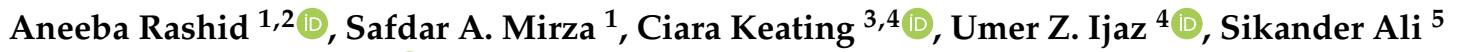 \\ and Luiza C. Campos $2, *$ (D) \\ 1 Department of Botany, GC University Lahore, Lahore 54000, Pakistan; aneebarashid@yahoo.com (A.R.); \\ safdaralimirza@gcu.edu.pk (S.A.M.) \\ 2 Department of Civil, Environmental and Geomatic Engineering, University College London, \\ London WC1E 6BT, UK \\ 3 Institute of Biodiversity, Animal Health \& Comparative Medicine, University of Glasgow, \\ Glasgow G12 8QQ, UK; ciara.keating@glasgow.ac.uk \\ 4 Division of Infrastructure and Environment, James Watt School of Engineering, University of Glasgow, \\ Glasgow G12 8LT, UK; umer.ijaz@glasgow.ac.uk \\ 5 Institute of Industrial Biotechnology (IIB), GC University Lahore, Lahore 54000, Pakistan; \\ prof.dr.sikanderali@gcu.edu.pk \\ * Correspondence: 1.campos@ucl.ac.uk
}

Citation: Rashid, A.; Mirza, S.A.; Keating, C.; Ijaz, U.Z.; Ali, S.;

Campos, L.C. Machine Learning Approach to Predict Quality Parameters for Bacterial Consortium-Treated Hospital Wastewater and Phytotoxicity Assessment on Radish, Cauliflower Hot Pepper, Rice and Wheat Crops. Water 2022, 14, 116. https://doi.org/ $10.3390 / \mathrm{w} 14010116$

Academic Editor: Paola Verlicchi

Received: 20 October 2021

Accepted: 20 December 2021

Published: 5 January 2022

Publisher's Note: MDPI stays neutral with regard to jurisdictional claims in published maps and institutional affiliations.

Copyright: (C) 2022 by the authors. Licensee MDPI, Basel, Switzerland. This article is an open access article distributed under the terms and conditions of the Creative Commons Attribution (CC BY) license (https:// creativecommons.org/licenses/by/ $4.0 /)$.

\begin{abstract}
Raw hospital wastewater is a source of excessive heavy metals and pharmaceutical pollutants. In water-stressed countries such as Pakistan, the practice of unsafe reuse by local farmers for crop irrigation is of major concern. In our previous work, we developed a low-cost bacterial consortium wastewater treatment method. Here, in a two-part study, we first aimed to find what physico-chemical parameters were the most important for differentiating consortium-treated and untreated wastewater for its safe reuse. This was achieved using a Kruskal-Wallis test on a suite of physico-chemical measurements to find those parameters which were differentially abundant between consortium-treated and untreated wastewater. The differentially abundant parameters were then input to a Random Forest classifier. The classifier showed that 'turbidity' was the most influential parameter for predicting biotreatment. In the second part of our study, we wanted to know if the consortium-treated wastewater was safe for crop irrigation. We therefore carried out a plant growth experiment using a range of popular crop plants in Pakistan (Radish, Cauliflower, Hot pepper, Rice and Wheat), which were grown using irrigation from consortium-treated and untreated hospital wastewater at a range of dilutions (turbidity levels) and performed a phytotoxicity assessment. Our results showed an increasing trend in germination indices and a decreasing one in phytotoxicity indices in plants after irrigation with consortium-treated hospital wastewater (at each dilution/turbidity measure). The comparative study of growth between plants showed the following trend: Cauliflower $>$ Radish $>$ Wheat $>$ Rice $>$ Hot pepper. Cauliflower was the most adaptive plant (PI: $-0.28,-0.13,-0.16,-0.06)$ for the treated hospital wastewater, while hot pepper was susceptible for reuse; hence, we conclude that bacterial consortium-treated hospital wastewater is safe for reuse for the irrigation of cauliflower, radish, wheat and rice. We further conclude that turbidity is the most influential parameter for predicting bio-treatment efficiency prior to water reuse. This method, therefore, could represent a low-cost, low-tech and safe means for farmers to grow crops in water stressed areas.
\end{abstract}

Keywords: hospital wastewater; bacterial consortium treatment; machine learning; Random Forest classifier; phytotoxicity; crop irrigation 


\section{Introduction}

Hospital wastewater production, unsafe disposal and management is a large-scale problem across the globe. Developed countries generate from 0.4 to $1.2 \mathrm{~m}^{3} /$ bed/day, while developing countries produce from 0.2 to $0.4 \mathrm{~m}^{3} /$ bed/day [1-6]. Pakistan is a developing country, but its untreated hospital wastewater accounts for $\sim 0.4-0.8 \mathrm{~m}^{3} /$ bed/day $[7,8]$, which is the usual range for developed countries. Much of this wastewater is discharged without treatment $[9,10]$. The Government of Pakistan $(\mathrm{GoP})$ has set strict safety regulations to ensure safe hospital waste management as an extension to the Pakistan Environmental Protection Act, 1997 [11]. The GoP has also set specific ranges for the National Environment Quality Standards (NEQs) for the physicochemical characteristics of wastewater before discharge, i.e., $\mathrm{pH}(6.6-8.5)$, total suspended solids (TSS) $(<500 \mathrm{mg} / \mathrm{L})$, total dissolved solids (TDS) (1000 mg/L), chemical oxygen demand (COD) (150-400 mg/L), biological oxygen demand (BOD5) (80-250 mg/L), turbidity (5 NTU), As (0.05 mg/L), Cd (0.01 mg/L), Cr $(0.05 \mathrm{mg} / \mathrm{L}), \mathrm{Pb}(0.05 \mathrm{mg} / \mathrm{L})$ and $\mathrm{Ni}(0.02 \mathrm{mg} / \mathrm{L})$ [12]. Nonetheless, the discharge of untreated hospital wastewater that shows physicochemical characteristics beyond the range limits has been reported, due to poor enforcement of these laws [4,13-15]. Hospital wastewater is particularly harmful if discharged untreated due to the spread of pharmaceutical pollutants $[16,17]$ and heavy metals $[9,16]$ in the aquatic environment. These pharmaceutical pollutants and heavy metals are recalcitrant in nature [18-20]. Heavy metals, such as Arsenic (As), Chromium (Cr), Lead (Pb), Nickel (Ni) and Cadmium (Cd) have the tendency to accumulate in water bodies $[15,19]$. Due to acute freshwater shortage, local farmers are utilising raw hospital wastewater for crop irrigation $[20,21]$. This results in the accumulation of toxic pollutants in crop plants $[4,15,18,19]$ that are comprised of pharmaceutic compounds, heavy metals and other toxic contaminants $[6,19,22-25]$. Subsequently, all these contaminants enter the food web [22-26] and harm aquatic $[27,28]$ and land $[26,27]$ animals, as well as human beings [26,27]. These heavy metals and pharmaceutic pollutants cause inexorable health problems [29-35]. They have been shown to impair the process of reproduction [36] and nervous and immune systems in humans [26,29]. Reducing their uptake is doable compared to overcoming their irrevocable hazards.

In our previous work, we have developed a simple, low-cost, biological method for hospital wastewater treatment using a consortium of three bacterial species (an Alcaligenes faecalis sp. and two Bacillus paramycoides spp.) isolated from hospital wastewater [37,38]. Our results highlighted that this biotreatment was effective for the degradation of heavy metals and pharmaceutical compounds and other parameters in raw hospital wastewater. For example, we demonstrated a biotreatment with this consortium that reduced heavy metal concentrations ( $\mathrm{Cr}, \mathrm{Pb}$ and $\mathrm{Ni}(100-86 \%)$ ) along with pharmaceutical pollutants (caffeine, diazepam, naproxen, octadecene, phenol and salicylic acid (100-74\%)) from hospital wastewater after biotreatment. Moreover, we observed the reduction of a range of wastewater quality indicators, i.e., turbidity, colour, BOD5, COD, biodegradability index (BI), electrical conductivity (EC), salinity, TSS and TDS [90-26\%] (Table 1). However, testing a suite of wastewater parameters separately can be challenging and expensive in low-middle income countries, and even more challenging in rural farm settings [39].

$\mathrm{COD}$ and $\mathrm{BOD}$ are the most conventional quality parameters used in predicting treatment efficiencies [40]. However, these fail to consider emergent and toxic contaminants (heavy metals, for example). Whilst one is disposed to acquiring an exhaustive set of parameters to differentiate treatment groups, some parameters may not change at all. For acquiring a low-tech solution, the use of artificial intelligence (AI) and Machine Learning (ML) is convenient to predict what is the most important parameter for the biotreatment efficiency. Recently, authors have predicted biological wastewater treatment efficiency prior to irrigation using various ML models, e.g., Adaptive Neuro Fuzzy Inference System (ANFIS), Artificial Neural Networks (ANN), Fuzzy Logic (FL) and Neuro-Fuzzy (NF) [40-42]. The Random Forest (RF) classifier method is an emerging ML method that has been used previously for monitoring urban wastewater [43]. The method also successfully predicted the performance of the adsorption of six heavy metals ( $\mathrm{As}, \mathrm{Cd}, \mathrm{Cu}, \mathrm{Ni}, \mathrm{Pb}$ and $\mathrm{Zi}$ ) in biochar 
within real waters and wastewaters [44]. To explore this further, RF classifier methods are typically applied, and their accuracy is established either through quality of fit criteria or through importance measures that delineate which parameters lead to better fit.

Table 1. Hospital Wastewater Quality Parameters.

\begin{tabular}{ccccc}
\hline \multirow{2}{*}{$\begin{array}{c}\text { Quality } \\
\text { Parameters }\end{array}$} & Units & \multicolumn{2}{c}{ Hospital Wastewater } & NEQS \\
\cline { 2 - 4 } & & Untreated & Treated & [12] \\
\hline Temperature & ${ }^{\circ} \mathrm{C}$ & 25 & 4 & $=<3$ \\
Turbidity & $\mathrm{NTU}$ & $51^{* * *}$ & $5^{* * *}$ & 5 \\
BOD & $\mathrm{mg} / \mathrm{L}$ & $246^{* * * *}$ & $78^{* * * *}$ & $80-250$ \\
Colour & $\mathrm{PCU}$ & $188^{* * * *}$ & 55 & - \\
TSS & $\mathrm{mg} / \mathrm{L}$ & $2300^{* * * *}$ & $483^{* * * *}$ & $<500$ \\
COD & $\mathrm{mg} / \mathrm{L}$ & $396^{* * * *}$ & $260^{* * * *}$ & $150-400$ \\
BI & - & 0.62 & 0.3 & - \\
EC & $\mathrm{ms} / \mathrm{cm}$ & $444^{* * * *}$ & $267^{* * * *}$ & - \\
Salinity & $\mathrm{pg} / \mathrm{L}$ & $0.2^{* *}$ & $0.1^{* *}$ & - \\
TDS & $\mathrm{mg} / \mathrm{L}$ & $296^{* * * *}$ & $220^{* * * *}$ & 1000 \\
Chromium & $\mathrm{mg} / \mathrm{L}$ & 1.8 & $\mathrm{Nd}$ & 0.05 \\
Nickel & $\mathrm{mg} / \mathrm{L}$ & $1.8^{*}$ & $\mathrm{Nd}$ & 0.02 \\
Lead & $\mathrm{mg} / \mathrm{L}$ & 0.17 & $\mathrm{Nd}$ & 0.05
\end{tabular}

Note: $\mathrm{Nd}=$ Not detected; Significance (Welch's test) between treated and untreated hospital wastewater is indicated by $p<0.01^{* *}, p<0.001^{* * *}, p<0.0001^{* * * *}$.

The present study includes two interdependent analyses. First, we aim to predict the quality parameters in hospital wastewater treated with a bacterial consortium (an Alcaligenes faecalis sp. and two Bacillus paramycoides spp.) using a Kruskal-Wallis test to identify the wastewater parameters that differentiate the treatment groups, and apply a Random Forest classifier on these reduced parameters to provide feature-wise importance measures for these parameters, thus highlighting the important parameter/s to consider in differentiating treatment efficiency for treated hospital wastewater application. Second, we aim to provide a phytotoxicity assessment for two purposes: to see whether our predicted quality parameter/s align with the phytotoxicity results and to analyse the response of plants (growth) on the reuse of treated hospital wastewater. We assess the seedling lengths and biomass measurements, germination indices and phytotoxicity indices for five crop species (radish, cauliflower, hot pepper, rice and wheat) grown in the treated wastewater and compare their responses in terms of growth to see which crop plants are more adaptive for wastewater reuse.

\section{Materials and Methods}

\subsection{Wastewater Treatment and Quality Parameters}

A bacterial consortium (an Alcaligenes faecalis sp. and two Bacillus paramycoides spp.) was added to deionized water $(10 \mathrm{~mL})$ in a test tube $(20 \mathrm{~mL})$. A consortium suspension was hence formed with a set value of optical density (OD) of 1. OD was kept the same to ensure an equal amount of three bacterial species in suspension. Treatment consisted of adding $10 \%$ of the consortium suspension to raw untreated autoclaved hospital wastewater and incubation at $37^{\circ} \mathrm{C}$ (optimal temperature for bacterial growth) in a shaking incubator for $48 \mathrm{~h}$. The control of this treatment was distilled water. After $48 \mathrm{~h}$ of incubation, this sample was centrifuged for $15 \mathrm{~min}$ (speed $=8000 \mathrm{~g} / \mathrm{min}$ ). The supernatant was shifted to a polypropylene falcon tube $(15 \mathrm{~mL})$. This supernatant was considered as treated hospital wastewater. The quality parameters selected for untreated and treated hospital wastewater were as follows: temperature, turbidity, BOD, colour, TSS, COD, BI, EC, salinity, TDS and heavy metals (Table 1). 


\subsection{Machine Learning Approach}

\subsubsection{Kruskal-Wallis Test}

The non-parametric data was autoscaled in such a way that all the features were of equal weights. The Kruskal-Wallis test was performed to see if these features discriminate between treated and untreated categories of hospital wastewater. Because the test was applied independently on all the acquired parameters, the Benjamini and Hochberg procedure was applied to adjust $p$-values for multiple comparisons [45]. Only those features were retained where the adjusted $p$-value was $<0.05$.

\subsubsection{Random Forest (RF) Classifier}

The RF classification method is a machine learning algorithmic technique that helps in classifying data with the help of decision trees [46]. The Random Forest classifier was applied on the discriminating features (quality parameters selected) from the previous step. After training the classifier, we utilized two measures: Mean Decrease in Accuracy gives an estimate of classifier performance if each feature is removed from training, resulting in reduced accuracy; whilst Mean Decrease in Gini looks at how pure class memberships are in terms of probabilities. A higher mean decrease in Gini index indicates that the classification is pure with the probability of achieving one category maximised.

\subsection{Phytotoxicity Assessment}

Phytotoxicity is a measure to assess any delay, hindrance or inhibition in plant growth caused by chemical compounds (pharmaceutics, phytotoxins, etc.), heavy metals or environmental factors (soil contamination, etc.) [47]. The phytotoxicity assessment comprised germination experiments that yielded seedling germination and phytotoxicity indices followed by statistical analyses.

\subsubsection{Germination Experiments}

Five different types of certified crop seeds were procured from the Seed Certification Department, Lahore, Punjab. The crop seed varieties were Raphanus sativus L. (Radish) var. Radish Minto Early, Brassica oleracea L. (Cauliflower) var. Cauliflower 2801, Capsicum annuum L. (Hot pepper) var. Seminis Hybrid Hot pepper SKY LINE 3, Triticum aestivum L. (Wheat) var. FSD-2008 and Oryza sativa L. (Rice) var. PS-2 (PK-112). The seeds were germinated in sterilised petri plates watered with four different dilutions $(25,50,75$ and $100 \%$ ) of untreated and treated hospital wastewater, as described in Rashid et al. [37]. The controls for the experiment were distilled water and tap water.

\subsubsection{Germination Indices (GI)}

The germination indices of three crops were calculated by multiplying the relative seedling germination and root growth. Lower GI values indicate the presence of EC and heavy metals within the seedlings [37,48], whereas higher GI values show safe removal of these physicochemical parameters from the seedlings [37,48]. The values were calculated using the following equation [37]:

$$
\text { Germination index }=\frac{(\text { Germinated seeds } \times \text { Average root length }) \text { for sample }}{(\text { Germinated seeds } \times \text { Average root length }) \text { for control }} \div 100
$$

\subsubsection{Phytotoxicity Indices (PI)}

The most sensitive parameter to assess the biotreatment efficiency is phytotoxicity index. A positive value indicates lower toxicity [49], whereas its negative value means the seedlings are contaminant-free and non-lethal [50]. Values of PI indices cause toxicity in four categories: low, medium, high, and very high [49,51]. These values range from 0 to 
$-0.25,-0.25$ to $-0.5,-0.5$ to -0.75 and -0.75 to -1 , respectively [ 49,51$]$. The values were calculated using the following equation [52]:

$$
\text { Phytotoxicity index }=1-\frac{\text { Root length of sample }}{\text { Root length of control }}
$$

\subsection{Statistical Analysis}

One-way ANOVA was used to analyse the data statistically using GraphPad Prism ${ }^{\circledR}$ 2020. The comparison of the obtained data was carried out by $t$-test using Welch's correction (with two-tailed $p$-values) [53]. The differences of comparisons were significant when $p$-values were $<0.05$. Associated statistical calculations were carried out using Sidak's multiple comparison testing. These comparisons were assessed between control (distilled water-DW) along with each treatment at varying concentration levels (Tap Water-TW as control, Raw wastewater 25\% (R25), Treated wastewater 25\% (T25), Raw wastewater $50 \%$ (R50), Treated wastewater 50\% (T50), Raw wastewater 75\% (R75), Treated wastewater $75 \%$ (T75), Raw wastewater 100\% (R100) and Treated wastewater 100\% (T100)). Similarly, the comparisons were made between raw wastewaters within each concentration level and the corresponding treated wastewaters (e.g., Raw wastewater 25\% (R25) and Treated wastewater $25 \%$ (T25)).

\section{Results and Discussions}

\subsection{Prediction of Quality Parameters}

The results of the Kruskal-Wallis test (Figure 1) shows which wastewater quality indicator parameters discriminate between Treated and Untreated hospital wastewater categories, highlighting adjusted $p$-values. All the parameters were discriminating significantly (TSS padj $=1.3655 \times 10^{-7}$, BOD padj $=1.3655 \times 10^{-7}$, Turbidity padj $=1.3655 \times 10^{-7}$, Colour padj $=1.3655 \times 10^{-7}$, BOD_COD padj $=9.3264 \times 10^{-6}$, COD padj $=6.7712 \times 10^{-5}$, $\mathrm{pH}$ padj $=0.00014423, \mathrm{EC}$ padj $=0.0016633$, Salinity padj $=0.0049779$, Chromium padj $=0.013416$, Nickel padj $=0.018595$, Lead padj $=0.040042$, TDS padj $=0.049674)$. The values for heavy metals in treated wastewater were reduced to zero. Therefore, the upregulation for these abundance values in Figure 1 relates to $p$-values of comparison of the untreated and treated data. Next, using these parameters we applied a Random Forest classifier. A confusion matrix aids in evaluating the correctness of our classification model. The confusion matrix here showed that we have obtained nearly perfect results, i.e., where those that are labelled as "Treated" are correctly classified as "Treated" and vice versa (Figure 2). Turbidity, BOD and colour showed the highest mean decrease accuracy, with values close to 16, while TSS had a value of 15 (Figure 3a). The mean decrease in Gini index was highest for turbidity (3), colour (2.9), BOD (2.8) and TSS (2.5) parameters (Figure 3b).

In light of the standard methods for wastewater quality analysis, five wastewater quality predicting parameters have been used in machine learning, i.e., BOD [14], COD [41,54-56], TSS [41,52,56], TDS [41] and turbidity [57,58]. The present RF classification successfully used artificial intelligence to predict twelve quality parameters between wastewater that was treated with the bacterial consortium versus untreated wastewater. Up to an $88 \%$ accuracy has been obtained in predictive analysis for industrial wastewater in the past [59]. The confusion matrix of our RF classifier showed nearly perfect results based on decision trees, highlighting the clear differentiation between treated and untreated wastewater. The results also suggested that turbidity was the most influential parameter to predict the effective biotreatment. Our results agree well with previous ML analyses using turbidity as a quality parameter for drinking water [57] and pharmaceutical wastewater treatment [58]. Turbidity represents a low-cost and simple measure of water quality. Thus, overall, this low-cost consortium method for wastewater treatment could easily be implemented at a small-scale on individual farms using turbidity as a measure to assess treatment efficiency prior to irrigation. Furthermore, turbidity in wastewater (due to the presence of contaminants) directly harms plant growth $[42,60]$. These plants directly impact 
animal and human life through consumption [60]. Hence, the phytotoxicity assessment on crop plants was carried out further to see the impact of treatment efficiency as predicted by our RF classifier.

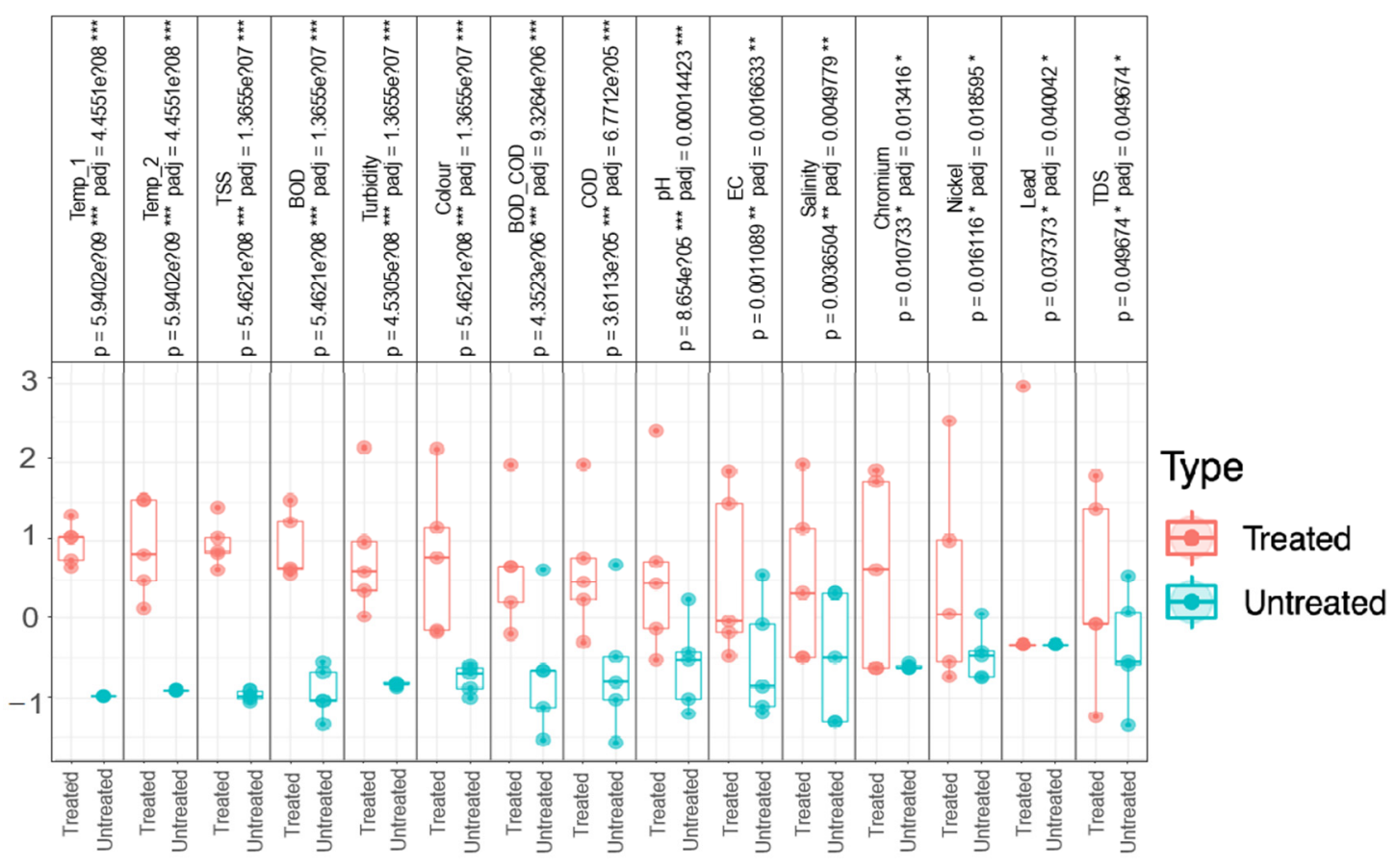

Figure 1. Box-plot graph showing the results of a Kruskal-Wallis statistical test to determine which of the water quality parameters (TSS, BOD, Turbidity, Colour, BOD_COD, COD, pH, EC, Salinity, Chromium, Nickel, Lead, TDS) were discriminating between the Untreated wastewater (in blue) and the Treated biotreated hospital wastewater (in red) on the $x$-axis and the autoscaled abundance on the $y$-axis. The statistical significance values are denoted within the box plots with symbol * and are indicated by $p<0.05^{*}, p<0.01^{* *}, p<0.001^{* * *}, p<0.0001^{* * * *}$.

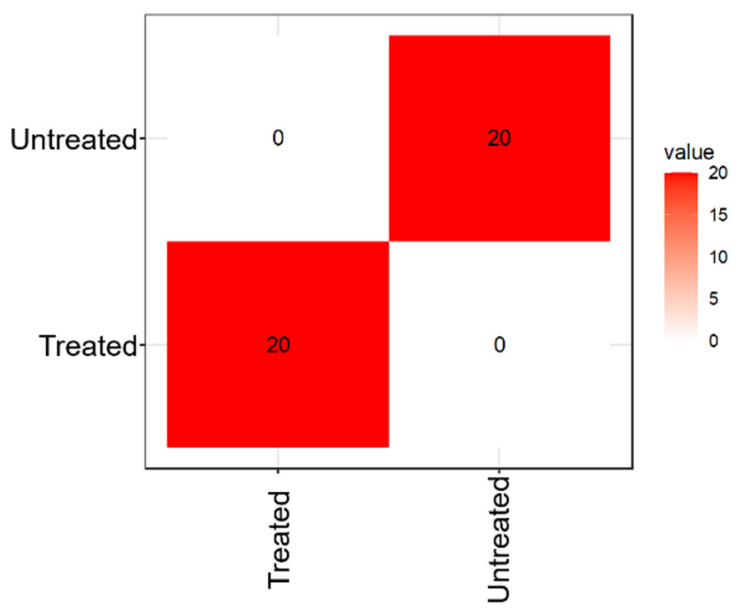

Figure 2. Confusion matrix for the water quality parameters in a Random Forest classifier between Treated and Untreated biotreated hospital wastewater. 

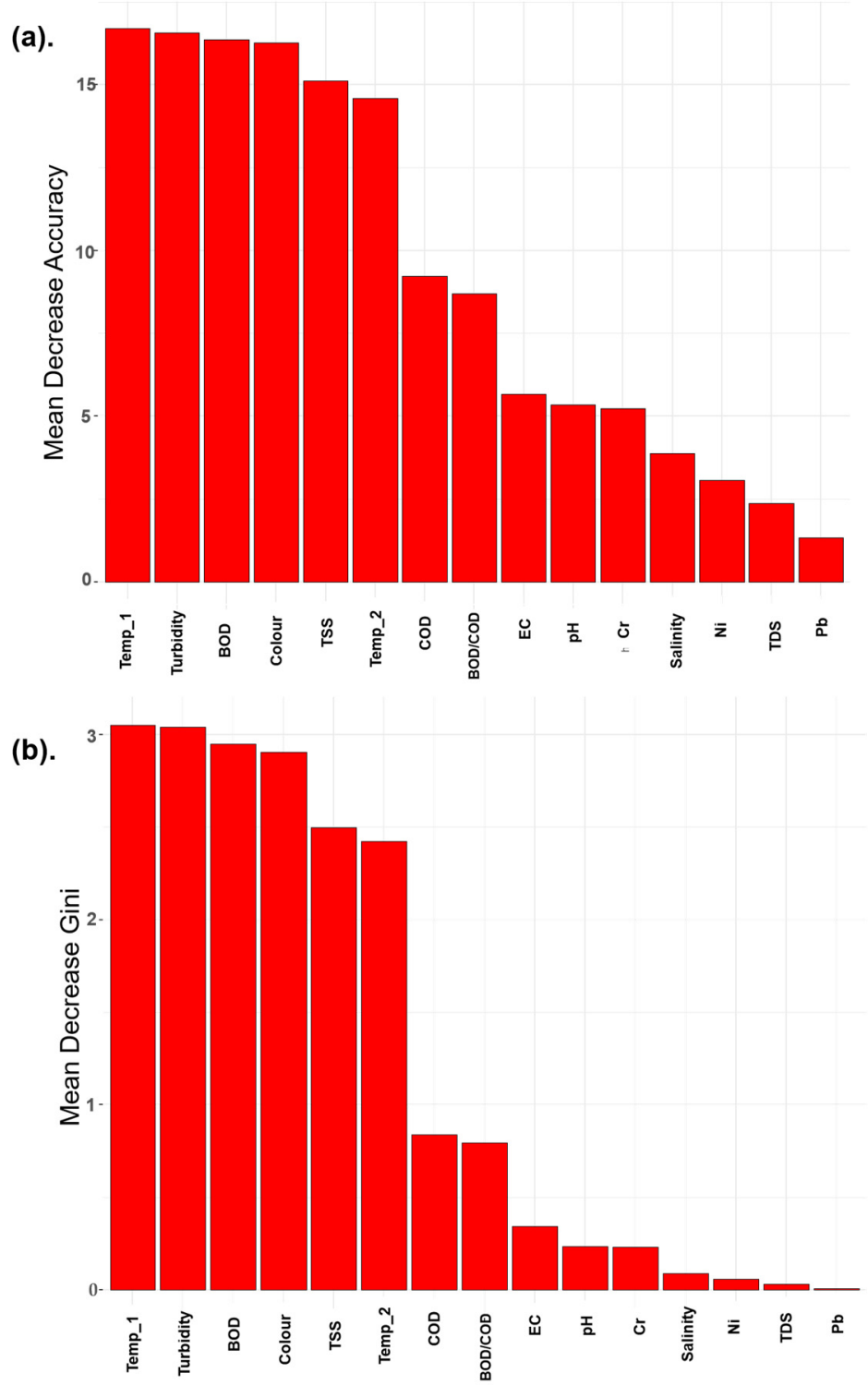

Figure 3. Bar-plots showing (a) the mean decrease in accuracy of water quality parameters sorted in terms of their importance; (b) the mean decrease in Gini of water quality parameters sorted in terms of their importance.

\subsection{Phytotoxicity Assessment of the Re-Use of Treated Hospital Wastewater for Crop Irrigation}

The lengths and biomass of seedling roots and shoots were measured on a daily basis and compared to controls after seedling germination (Figure $4 \mathrm{a}-\mathrm{e}$ ). 
(a) Plant 1

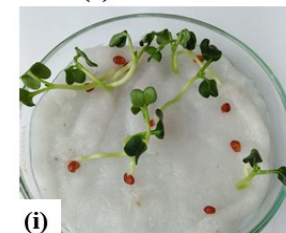

(i)

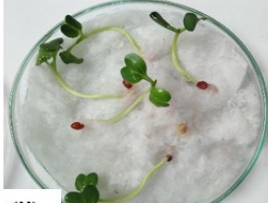

(ii)

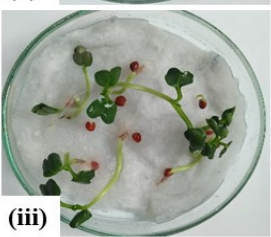

(b) Plant 2

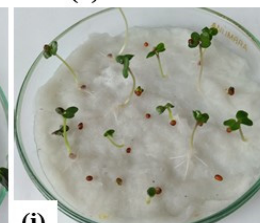

(i)

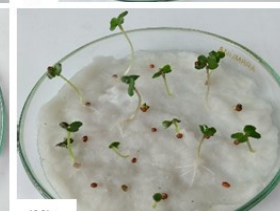

(ii)

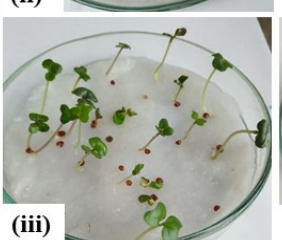

(c) Plant 3

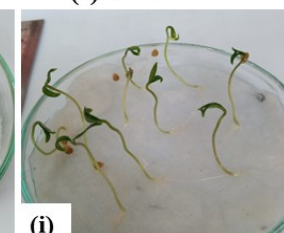

(i)

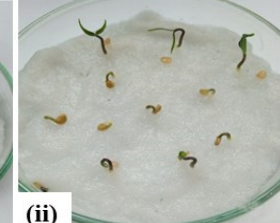

(d) Plant 4
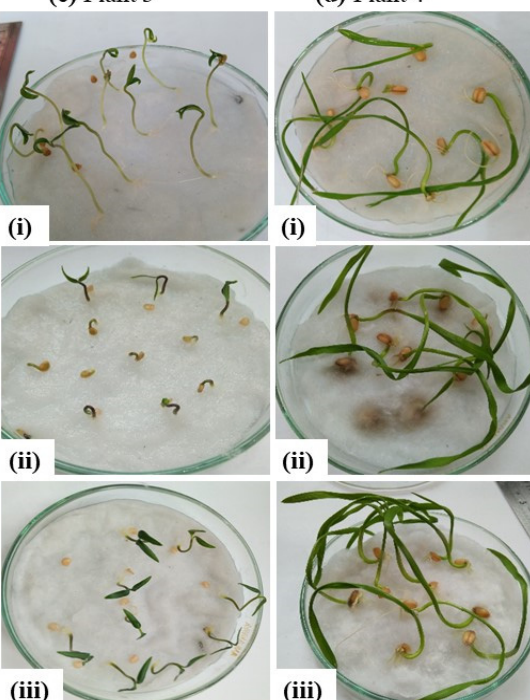

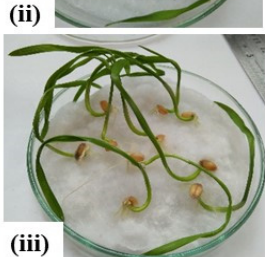

(e) Plant 5
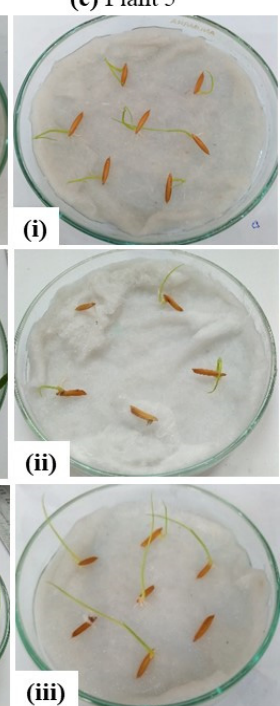

Figure 4. (a) Plant 1: R. sativus (Radish) seedlings grown in 100\% concentration of (i) control (distilled water), (ii) untreated and (iii) treated hospital wastewater after two weeks; (b) Plant 2: B. oleracea L. (Cauliflower) seedlings grown in $100 \%$ concentration of (i) control (distilled water), (ii) untreated and (iii) treated hospital wastewater after two weeks; (c) Plant 3: C. annuum L. (Hot pepper) seedlings grown in $100 \%$ concentration (i) control (distilled water), (ii) untreated and (iii) treated hospital wastewater after two weeks; (d) Plant 4: T. aestivum L. (Wheat) seedlings grown in 100\% concentration (i) control (distilled water), (ii) untreated and (iii) treated hospital wastewater after two weeks; (e) Plant 5: O. sativa L. (Rice) seedlings grown in 100\% concentration (i) control (distilled water), (ii) untreated and (iii) treated hospital wastewater after two weeks.

\subsubsection{Radish Crop}

The seedling lengths and weights were compared between irrigation from untreated and treated hospital wastewater concentrations (25, 50, 75 and $100 \%)$ tested separately. It was found that the seedling length for both shoots and roots were elongated in treated hospital wastewaters at all concentrations (shoots: $3.1-4.7 \mathrm{~cm}$; roots: $2.9-4.4 \mathrm{~cm}$ ). Similarly, the seedling weights for both shoot and root (fresh and dry) were greater when grown in treated hospital wastewater concentrations (shoot fresh weight: $0.055-0.158 \mathrm{~g}$; shoot dry weight: $0.02-0.089 \mathrm{~g}$; root fresh weight: $0.011-0.043 \mathrm{~g}$; root dry weight: $0.004-0.021 \mathrm{~g}$ ) (Table S1). Increased lengths and biomass values with treated wastewater (comparable or greater to the control conditions) indicates that the radishes were not impacted by the treated wastewater but were impacted by the untreated wastewater.

In the present work, the radish seeds grown in treated hospital wastewaters $(25,50,75$ and $100 \%$ ) showed an increase in GI values from $75-86 \%$ to $102-108 \%$. (Figure $5 a$ ). The germination indices for all crop seedlings grown in four untreated hospital wastewater concentrations showed low values that reflect the presence of six organic toxic pollutants (caffeine, diazepam, naproxen, octadecene, phenol and salicylic acid) which were identified in our previous study [38]. These values also reflect the presence of three heavy metals in raw hospital wastewater $(\mathrm{Cr}, \mathrm{Pb}$ and $\mathrm{Ni})$ [38]. The reduced $\mathrm{GI}$ values hinder the relative germination of seedlings and root growth, accordingly [61]. Higher GI values for seeds grown in treated hospital wastewaters indicates the reduction or removal of heavy metals. High GI values with treated wastewater indicates that the radishes are not impacted by the treated wastewater in the same way as the untreated. This shows that the treated wastewater may be safe for irrigating radishes. Likewise, the decrease in EC and turbidity in hospital wastewater after biotreatment is an indication of treatment efficiency [37]. The present GI values for seeds grown in treated hospital wastewater endorse decreased EC 
and turbidity value, the same as those predicted by the RF classifier, and hence proves the treatment efficiency.

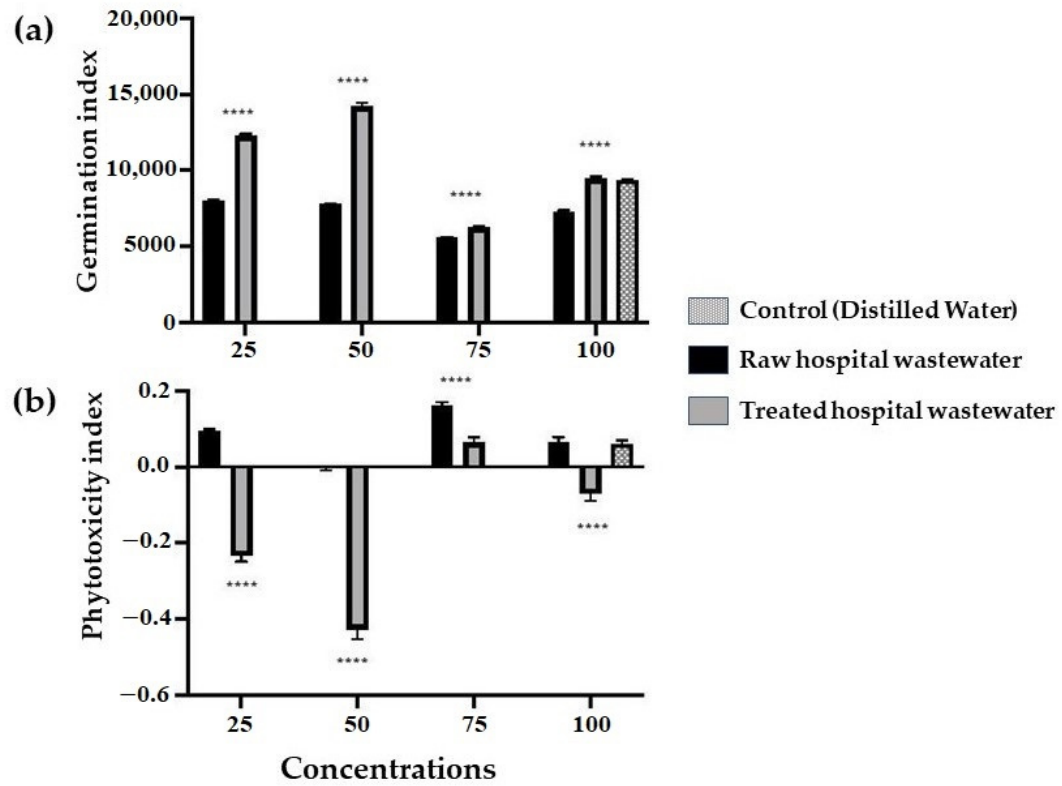

Figure 5. (a) Germination indices of Radish seeds grown in untreated and treated hospital wastewaters; (b) Phytotoxicity indices of Radish seeds grown in untreated and treated hospital wastewaters. Significance (Welch's test) between treated and untreated hospital wastewater is indicated by $p<0.0001^{* * * *}$.

Previously, the phytotoxicity assessment in plants has been carried out using one growth predicting factor, i.e., GI [62]. The present study is significantly different as it chose two growth predicting factors, GI and PI. PI is a very sensitive indicator for assessing the toxicity level of heavy metals and pharmaceutic compounds among plants [50]. It shows to what extent the pharmaceutic pollutants, chemical compounds or heavy metals have either stunted or harmed plant growth. The PI values for radish seeds when grown in treated hospital wastewater were proven significant statistically in comparison to those grown in untreated hospital wastewater. The PI values of seeds grown in untreated hospital wastewater concentrations $(25,50,75$ and $100 \%)$ were positive $(0.1,0,0.16,0.06$, respectively). This indicates a medium to large lethal effect on the growth of seedlings (Figure $5 b$ ). The positive values of PI for seeds grown in specific untreated wastewater concentrations may be ascribed to the occurrence of nitrogen $(\mathrm{N})$, phosphorous $(p)$ and potassium (K) [52]. In contrast, the seeds grown in three treated hospital wastewaters (25, 50 and $100 \%)$ exhibited negative values of PI $(-0.23,-0.42$ and -0.06$)$. This indicates strong stimulatory effect on seedling growth. One treated hospital wastewater concentration (75\%) showed positive value of PI (0.06) (Figure 5b). However, this PI value was reduced from 0.16 to 0.06 , which shows a reduction in toxicity level. Previously, reduction in positive values of PI for the barley plant has been attributed to diluted concentrations of treated wastewater, which indicated removal of phenol and heavy metals [52]. In our work, crop irrigation with treated hospital wastewater leads to the reduction in PI value, which may also be due to various reasons: heavy metal reduction $[63,64]$, reduction in phenols and supplementary organic complexes [65] and stress tolerances [66]. Radish roots are more sensitive towards the uptake of heavy metals and contaminants from the soil [67]; hence, the crop plant has more proximity towards inducing phytotoxicity. Therefore, lower (negative) PI values with treated wastewater in our results indicate that the radishes are not harmed by the treated wastewater in the same way as the untreated. Based on these findings, we conclude that the treated wastewater may be safe for reuse to irrigate radish crops. 


\subsubsection{Cauliflower Crop}

The lengths and weights of cauliflower seedlings were compared statistically when grown in the untreated and treated hospital wastewater concentrations $(25,50,75$ and $100 \%)$. The statistical measurements also specified that the mean lengths and weights were significant. The lengths of seedlings (shoots and roots) were found to be longer in treated hospital wastewater concentrations (shoots: $3.2-3.9 \mathrm{~cm}$; roots: $3.4-4.1 \mathrm{~cm}$ ). Similarly, the seedling weights for both shoot and root (fresh and dry) were greater when grown in treated hospital wastewater concentrations (shoot fresh weight: 0.04-0.029 g; shoot dry weight: $0.006-0.031 \mathrm{~g}$; root fresh weight: $0.006-0.029 \mathrm{~g}$; root dry weight: $0.002-0.031 \mathrm{~g}$ ) (Table S2). The cauliflower seeds grown in treated hospital wastewater $(25,50,75$ and $100 \%$ ) showed a rise in GI values from $55-80 \%$ to $62-142 \%$. (Figure $6 a$ ). The values for PI in seeds grown in untreated and treated hospital wastewater were significant statistically in comparison. The PI values for seeds grown in untreated hospital wastewaters $(25,50$, 75 and $100 \%)$ were positive $(0.09,0.16,0.14,0.06$, respectively). This indicates a medium lethal impact on the growth of seedlings (Figure $6 \mathrm{~b}$ ). Conversely, the seeds grown in three treated wastewater concentrations $(25,50,75$ and $100 \%)$ exhibited negative values of PI $(-0.28,-0.13,-0.16,-0.06)$, which indicates a stimulatory effect on seedling growth Cauliflower crop has shown low sensitivity towards accessing environmental pollution in the past [68]. Additionally, chromium has been proven to be the most harmful heavy metal for the growth of cauliflower plants [69]. In the present study, the reduction of chromium in treated hospital wastewater seems to contribute to the higher seedling length and biomass and higher GI values. Similarly, lower PI values with treated wastewater indicate that cauliflowers are not impacted by the treated wastewater in the same way as the untreated. This highlights the treatment efficiency and indicates that wastewater may be safe for irrigating cauliflowers.

(a)

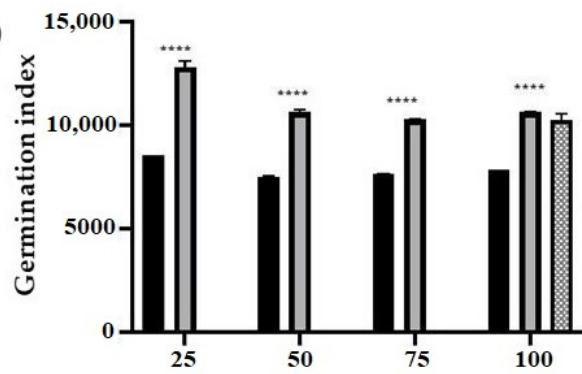

(b)

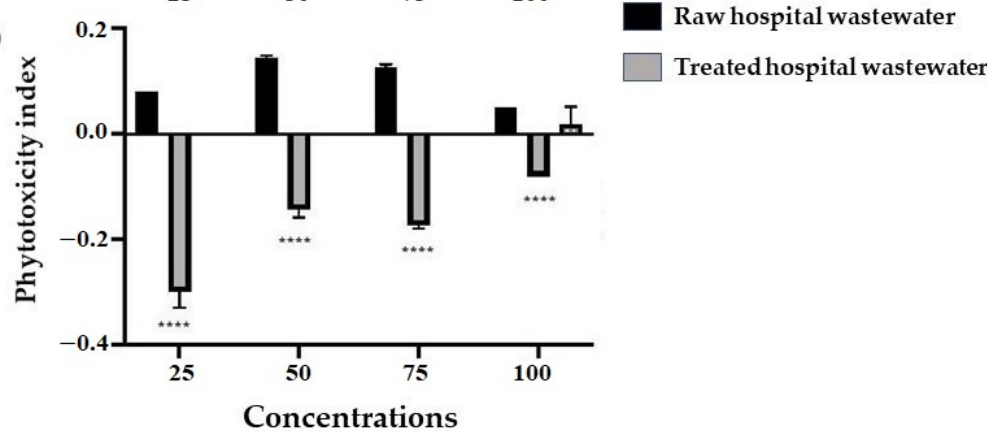

Figure 6. (a) Germination indices of Cauliflower seeds grown in untreated and treated hospital wastewaters; (b) Phytotoxicity indices of Cauliflower seeds grown in untreated and treated hospital wastewaters. Significance (Welch's test) between treated and untreated hospital wastewater is indicated by $p<0.0001^{* * * *}$.

\subsubsection{Hot Pepper Crop}

Hot pepper plants have been investigated in the past for phytotoxicity assessment of reusing treated industrial wastewaters, resulting in increased biomass [70-73]. The plant is more sensitive to lead concentrations than any other plant [74]. With reduced 
concentrations of lead in the wastewater, root and shoot lengths and the biomass of hot pepper plants were reported to be increased [74]. The present results endorse the previously reported findings. In the present study, the lengths of seedling (shoots and roots) were longer in treated wastewaters (shoots: $1.8-2.3 \mathrm{~cm}$; roots: $2-5.2 \mathrm{~cm}$ ). Additionally, the seedling weights for both shoot and root (fresh and dry) increased when grown in treated hospital wastewater concentrations (shoot fresh weight: 0.02-0.019 g; shoot dry weight: 0.006-0.05 g; root fresh weight: $0.011-0.019$ g; root dry weight: 0.003-0.008 g) (Table S3). The hot pepper seeds grown in treated hospital wastewater (25, 50, 75 and 100\%) showed an increase in GI values from $72-90 \%$ to $63-109 \%$. (Figure 7a). The PI values for seeds grown in untreated wastewaters $(25,50,75$ and $100 \%)$ were positive $(0.27,0.15,0.12$ and 0.09 , respectively). This indicates a medium lethal impact on the growth of seedling (Figure $7 \mathrm{~b}$ ). Conversely, the seeds grown in two treated hospital wastewater concentrations (25 and $100 \%)$ showed negative PI values $(-0.09$ and -0.58$)$. This also indicates a stimulatory effect on seedling growth as the PI values were lower than the control. Another two treated hospital wastewater concentration (50 and 75\%) showed positive values of PI ( 0.21 and 0.39$)$ (Figure 7b). In light of the available literature, heavy metal reduction $[63,64]$, reduction of phenols and supplementary organic compounds [65] may be the possible reasons that contributed to the positivity in phytotoxicity values.

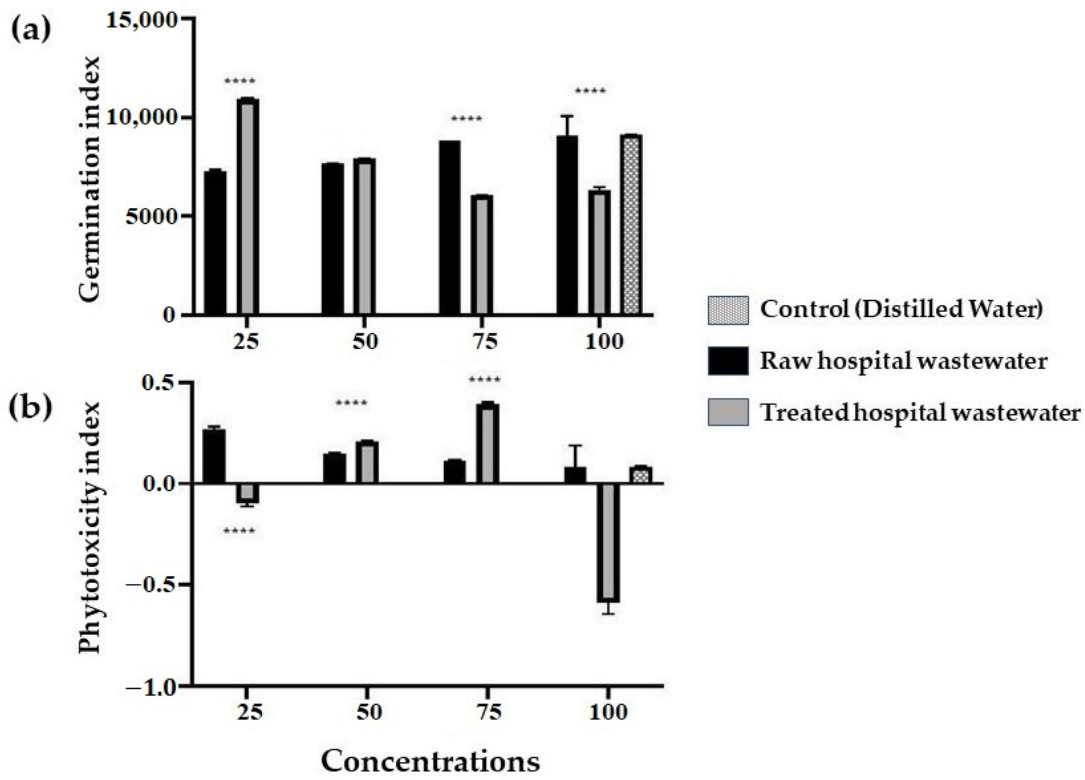

Figure 7. (a) Germination indices of Hot pepper seeds grown in untreated and treated hospital wastewaters; (b) Phytotoxicity indices of Hot pepper seeds grown in untreated and treated hospital wastewaters. Significance (Welch's test) between treated and untreated hospital wastewater is indicated by $p<0.0001^{* * * *}$.

\subsubsection{Wheat Crop}

Wheat showed increased seedling length for both shoots and roots in treated hospital wastewater concentrations (shoots: 7.1-9.9 cm; roots: 8.6-10.2 cm). Additionally, the seedling weights for both shoot and root (fresh and dry) were raised when grown in treated hospital wastewaters (shoot fresh weight: 0.077-0.122 g; shoot dry weight: 0.019-0.053 g; root fresh weight: $0.068-0.089 \mathrm{~g}$; root dry weight: $0.019-0.032 \mathrm{~g}$ ) (Table S4). The wheat seeds grown in treated hospital wastewaters (25, 50, 75 and 100\%) showed an increase in GI values from $79-106 \%$ to $106-126 \%$. (Figure $8 \mathrm{a}$ ). The PI values for wheat seeds grown in untreated hospital wastewaters $(25,50,75$ and $100 \%)$ were $0.10,0.10,-0.19,0.21$, respectively, which indicates a medium to low toxic effect on seedling growth (Figure $8 b$ ). Conversely, the seeds grown in three treated hospital wastewater concentrations (25, 50 and 100\%) showed negative PI values $(-0.26,-0.10$ and -0.12 , respectively). Another treated hospital 
wastewater concentration (75\%) showed a positive value of PI (0.06) (Figure 8b). Previously, wheat has showed positive PI values in phenol-containing industrial wastewaters [75]. Our work analyses a diverse range of pharmaceutical pollutants (caffeine, diazepam, naproxen, octadecene, phenol and salicylic acid) and heavy metals $(\mathrm{Ni}, \mathrm{Cr}, \mathrm{Pb})$ which are present in untreated hospital wastewater. The positive growth of wheat plants after irrigation with treated hospital wastewater indicates treatment efficiency.

(a)

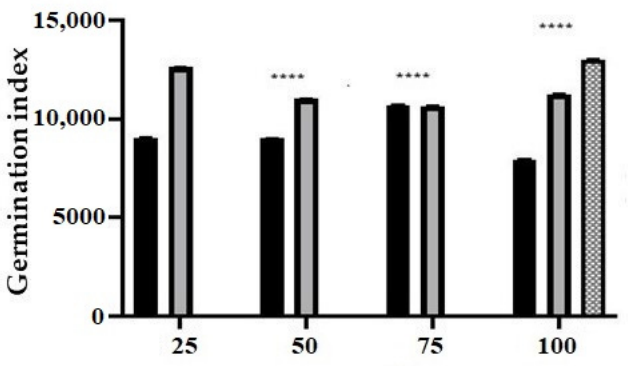

(b)

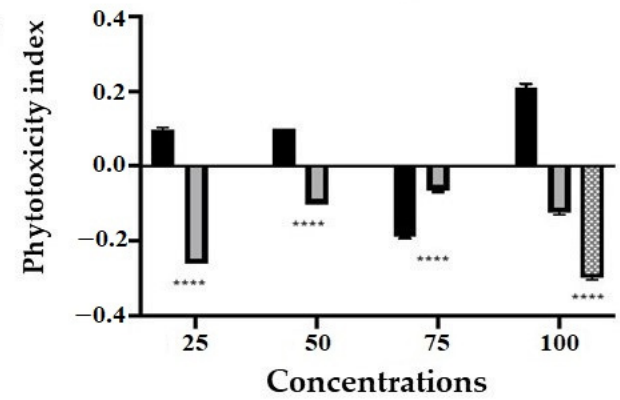

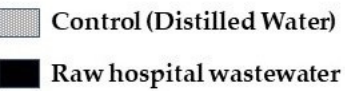

Treatedhospital wastewater

Figure 8. (a) Germination indices of Wheat seeds grown in untreated and treated hospital wastewaters; (b) Phytotoxicity indices of Wheat seeds grown in untreated and treated hospital wastewaters. Significance (Welch's test) between treated and untreated hospital wastewater is indicated by $p<0.0001^{* * * *}$.

\subsubsection{Rice Crop}

The results showed that the lengths of seedlings (shoots and roots) were increased in treated hospital wastewaters (shoots: $3.1-5.1 \mathrm{~cm}$; roots: $3.4-10.2 \mathrm{~cm}$ ). Additionally, the seedling biomass for both shoot and root (fresh and dry) increased when grown in treated hospital wastewater concentrations (shoot fresh weight: 0.008-0.015 g; shoot dry weight: 0.001-0.006 g; root fresh weight: 0.052-0.05 g; root dry weight: 0.023-0.032 g) (Table S5). The rice seeds grown in treated wastewaters (25, 50, 75 and 100\%) showed an increase in GI values from 36-90\% to $90-144 \%$. (Figure 9a). The PI values for seeds grown in untreated hospital wastewaters $(25,50,75$ and $100 \%)$ were positive $(0.60,0.27,0.42,0.42)$, which indicates a medium to high lethal effect on the growth of seedlings (Figure $9 b$ ). The seeds grown in three treated hospital wastewater concentrations (25, 50 and 100\%) showed PI values of $0.07,0.35$ and 0.59 , which were lower than the values of untreated hospital wastewater concentrations. Another treated hospital wastewater concentration $(75 \%)$ showed negative values of PI (-0.23) (Figure 9b). Recently, researchers found rice to be a sensitive crop plant for reusing treated wastewaters [76,77]. They observed inhibitory effects on seed germination and plant growth. Our work agrees with the existing work, with stimulatory growth of rice seedlings in the presence of treated wastewater where there is no turbidity. 
(a)

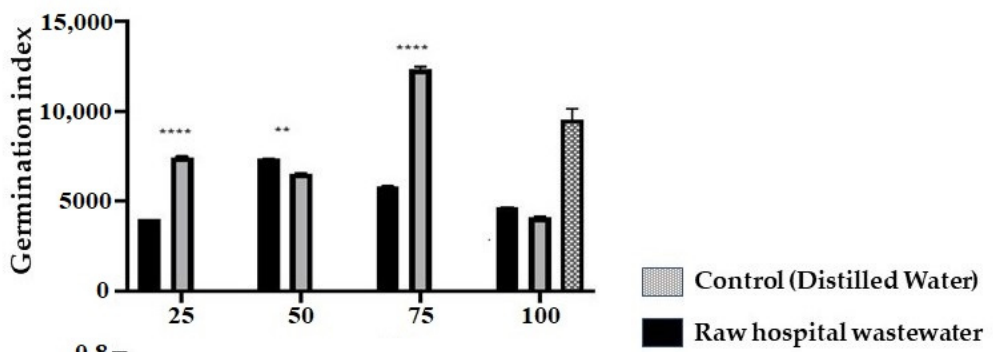

(b)

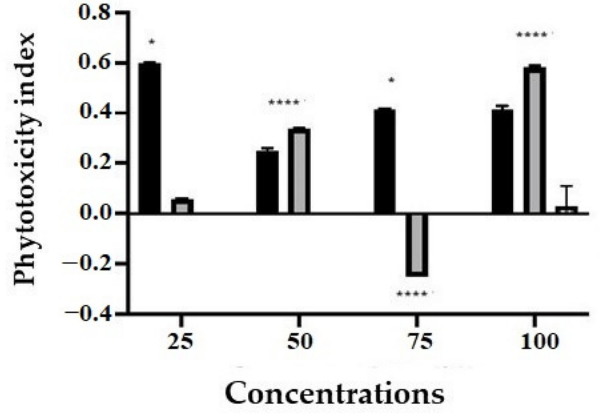

Treated hospital wastewater

Figure 9. (a) Germination indices of Rice seeds grown in untreated and treated hospital wastewaters; (b) Phytotoxicity indices of Rice seeds grown in untreated and treated hospital wastewaters. Significance (Welch's test) between treated and untreated hospital wastewater is indicated by $p<0.05$ *, $p<0.01^{* *}, p<0.0001^{* * * *}$.

Many researchers have stated that higher phytotoxicity indices in plants grown in untreated industrial wastewaters indicate toxicity induction in plants due to polluted water [32,78-81]. The present study has shown a significant reduction in phytotoxicity for these five crop plants grown in consortium-treated wastewater, which in turn confirms the efficiency of biotreatment. The comparatively increased germination and reduced phytotoxic analysis of the five crops for the treated wastewater is as follows: Cauliflower $>$ Radish $>$ Wheat $>$ Rice $>$ Hot pepper. The capacity to accumulate heavy metals is different in various types of plants, both on land as well as in aquatic plants [82,83]. Leafy and root vegetable crops absorb these metals more frequently than other vegetables [82]. Cauliflower crop showed the highest adaptability towards treated wastewater; although it has sensitivity towards chromium $[68,69]$, because chromium was absent in our treated wastewater, its GI was highest and PI values were lowest. Another contributing factor is the physiognomy of cauliflower as a flowering vegetable. Radish has more proximity towards inducing phytotoxicity [67], but as the treated wastewater neither had heavy metals nor pharmaceutic components beyond the acceptable NEQS range, it showed high GI values and low PI values. Wheat and rice showed improved growth and heavy metal tolerance with the application of reused wastewater $[75,84,85]$. Our work agrees with the previous study because our GI values were high and PI values were low, which are indicators of stimulatory plant growth. Hot pepper plants are vulnerable/sensitive to stress or pollutants [70-74]. A similar observation came to light in our work, where the plant showed sensitivity towards PI values even after the treatment. Because the other crops were fine, we can say that irrigation with treated wastewater in fact had a stimulatory effect on Cauliflower, Radish, Wheat and Rice. The phytotoxicity results highlight two key points: that the consortium-treated wastewater is safe for reuse for crop irrigation and that hot pepper plants are the most susceptible to growth under these conditions.

Our work shows the feasibility of the safe re-use of treated hospital wastewater for crop irrigation in water-stressed areas. Future work should include the following: a detailed assessment of any potential spread of antimicrobial resistance, translation of growth experiments to agricultural field sites, and research into how this consortiumtreatment method could be implemented in practice. The environmental sustainability of the consortium treatment may be assessed via. comparing it with other methods such as 
electrochemical and advanced oxidation for advanced hospital wastewater treatment to remove the toxic pollutants and to see which of the method is more sustainable/low-cost or low-tech. Furthermore, a life-cycle analysis could be performed [86-89].

\section{Conclusions}

The present study supports the successful prediction of quality parameters in bacterial consortium-treated hospital wastewater using a Random Forest classifier. The confusion matrix of the RF classifier showed nearly perfect results based on decision trees, highlighting the clear differentiation between treated and untreated wastewater. The results also suggested that turbidity was the most influential parameter to predict the most effective biotreatment. Turbidity represents a low-cost and simple measure of water quality. Thus, overall, this low-cost consortium method for wastewater treatment could easily be implemented at a small-scale on individual farms using turbidity as a measure to assess treatment efficiency prior to irrigation.

Turbidity indicates the presence of heavy metals and pharmaceutic pollutants in the wastewater which are potentially harmful for plant growth. Unstable plant growth directly impacts human life. Therefore, the phytotoxicity assessment on five widely grown crop plants was carried out to see the impact. The crop plants showed increased seedling lengths and biomass, high GI values and low PI values when grown in the treated wastewater. The PI values were either similar to the control or lower, which indeed shows a stimulatory effect, and therefore, treated wastewater with this bacterium consortium may be a safe option for irrigation of these crop plants. The comparative analysis of the five crops for germination and phytotoxicity is as follows: Cauliflower $>$ Radish $>$ Wheat $>$ Rice $>$ Hot pepper. Our work recommends the reuse of quality-predicted biotreated hospital wastewater; however, there is a further need to analyse the products of these crop plants to ensure their safe consumption. Moreover, environmentally sustainable advanced hospital wastewater treatment would be a gateway to achieve Sustainable Development Goals 6, 14 and 15.

Supplementary Materials: The following supporting information can be downloaded at: https: / / www.mdpi.com/article/10.3390/w14010116/s1, Table S1: Comparison of untreated (R25, R50, R75, R100) and treated (T25, T50, T75, T100) hospital wastewater concentrations on seedling growth of R. sativus (Radish) var. Radish Minto Early ( \pm Standard Deviation in brackets); Table S2: Comparison of untreated (R25, R50, R75, R100) and treated (T25, T50, T75, T100) hospital wastewater concentrations on seedling growth of B. oleracea (Cauliflower) var. Cauliflower 2801 ( \pm Standard Deviation in brackets); Table S3: Comparison of untreated (R25, R50, R75, R100) and treated (T25, T50, T75, T100) hospital wastewater concentrations on seedling growth of $\mathrm{C}$. annuum (Hot pepper) var. Seminis Hybrid Hot pepper SKY LINE 3 ( \pm Standard Deviation in brackets); Table S4: Comparison of untreated (R25, R50, R75, R100) and treated (T25, T50, T75, T100) hospital wastewater concentrations on seedling growth of T. aestivum (Wheat) var. FSD-2008 ( \pm Standard Deviation in brackets); Table S5: Comparison of untreated (R25, R50, R75, R100) and treated (T25, T50, T75, T100) hospital wastewater concentrations on seedling growth of O. sativa (Rice) var. PS-2 (PK-112) ( \pm Standard Deviation in brackets).

Author Contributions: Conceptualization, A.R.; methodology, A.R., S.A.M. and S.A.; software, C.K. and U.Z.I.; validation, A.R., S.A.M., S.A., L.C.C., C.K. and U.Z.I.; formal analysis, A.R.; investigation, A.R.; resources, A.R., S.A.M. and S.A.; data curation, A.R.; writing-original draft preparation, A.R.; writing-review and editing, A.R., C.K., L.C.C. and U.Z.I.; visualization, A.R.; supervision, S.A.M. and L.C.C.; project administration, S.A.M. and L.C.C.; funding acquisition, A.R. All authors have read and agreed to the published version of the manuscript.

Funding: A.R. is funded by the Higher Education Commission, Pakistan, under the 5000-Indigenous PhD Scholarship Program (PIN: 315-4354-2BS3-051) and International Research Support Initiative Program (PIN: IRSIP-44-BMS-81). U.Z.I. is supported by NERC, UK (NE/L011956/1) and EPRSC (EP/P029329/1 and EP/V030515/1). C.K. is supported by EPRSC (EP/P029329/1 and $\mathrm{EP} / \mathrm{V} 030515 / 1)$. 
Institutional Review Board Statement: Not applicable.

Informed Consent Statement: Not applicable.

Data Availability Statement: The data presented in this study are available on request from the corresponding author.

Acknowledgments: The authors acknowledge the Botany Department, Government College University, Lahore, for support during the research. The authors also acknowledge Kourosh Behzadian (University of West London) for the initial discussion on machine learning.

Conflicts of Interest: The authors declare no conflict of interest. The funders had no role in the design of the study; in the collection, analyses, or interpretation of data; in the writing of the manuscript; or in the decision to publish the results.

\section{References}

1. Minhas, P.S.; Saha, J.K.; Dotaniya, M.L.; Sarkar, A.; Saha, M. Wastewater irrigation in India: Current status, impacts and response options. Sci. Total Environ. 2022, 808, 152001. [CrossRef] [PubMed]

2. Majumder, A.; Gupta, A.K.; Ghosal, P.S.; Varma, M. A review on hospital wastewater treatment: A special emphasis on occurrence and removal of pharmaceutically active compounds, resistant microorganisms, and SARS-CoV-2. J. Environ. Chem. Eng. 2021, 9, 104812. [CrossRef] [PubMed]

3. Kumari, A.; Maurya, N.S.; Tiwari, B. Hospital wastewater treatment scenario around the globe. Curr. Dev. Biotechnol. Bioeng. 2020, 549-570. [CrossRef]

4. Al Aukidy, M.; Al Chalabi, S.; Verlicchi, P. Hospital Wastewater Treatments Adopted in Asia, Africa, and Australia. In Hospital Wastewaters. The Handbook of Environmental Chemistry; Verlicchi, P., Ed.; Springer: Berlin/Heidelberg, Germany, 2017 ; p. 60. [CrossRef]

5. Carraro, E.; Bonetta, S.; Bertino, C.; Lorenzi, E.; Bonetta, S.; Gilli, G. Hospital effluents management: Chemical, physical, microbiological risks and legislation in different countries. J. Environ. Manag. 2016, 168, 185-199. [CrossRef]

6. Rodriguez-Mozaz, S.; Chamorro, S.; Marti, E.; Huerta, B.; Gros, M.; Sànchez-Melsió, A.; Borrego, C.M.; Barceló, D.; Balcázar, J.L. Occurrence of antibiotics and antibiotic resistance genes in hospital and urban wastewaters and their impact on the receiving river. Water Res. 2015, 69, 234-242. [CrossRef]

7. Murtaza, G.; Zia, M.H. Wastewater Production, Treatment and Use in Pakistan, Final Country Report. UN-Water Activity Information System. In Proceedings of the Second Regional Workshop of the Project 'Safe Use of Wastewater in Agriculture, New Delhi, India, 16-18 May 2012.

8. Ministry of Water and Power. Pakistan Water Sector Strategy (PWSS): National Water Sector Profile, 5; Ministry of Water and Power, Office of the Chief Engineering Advisor: Islamabad, Pakistan, 2002.

9. Zafar, R.; Bashir, S.; Nabi, D.; Arshad, M. Occurrence and quantification of prevalent antibiotics in wastewater samples from Rawalpindi and Islamabad, Pakistan. Sci. Total Environ. 2021, 764, 142596. [CrossRef] [PubMed]

10. Meo, M.I.; Haydar, S.; Nadeem, O.; Hussian, G.; Mian, H.R. Characterization of hospital wastewater, risk waste generation and management practices in Lahore. Proc. Pak. Acad. Sci. 2014, 51, 317-329.

11. GoP/DoE. Hospital Waste Management Rules, 2005. S.R.O.1013 (1)/2005; Government of Pakistan (GoP), Ministry of Environment: Islamabad, Pakistan, 2005.

12. National Environment Quality Standards (NEQS). The Gazette of Pakistan; Ministry of Environment, Local Government and Rural Development, Government of Pakistan (GoP): Islamabad, Pakistan, 2000; pp. 1289-1294.

13. Qadir, M.; Wichelns, D.; Raschid-Sally, L.; McCornick, P.G.; Drechsel, P.; Bahri, A.; Minhas, P.S. The challenges of wastewater irrigation in developing countries. Agric. Water Manag. 2010, 97, 561-568. [CrossRef]

14. Jabeen, A.; Huang, X.; Aamir, M. The Challenges of water pollution, threat to public health, flaws of water laws and policies in Pakistan. J. Water Resour. Prot. 2015, 7, 1-11. [CrossRef]

15. Muhammad, N.; Nafees, M.; Ge, L.; Khan, M.H.; Bilal, M.; Chan, W.P.; Lisak, G. Assessment of industrial wastewater for potentially toxic elements, human health (dermal) risks, and pollution sources: A case study of Gadoon Amazai industrial estate, Swabi, Pakistan. J. Hazard. Mater. 2021, 419, 126450. [CrossRef]

16. Olicón-Hernández, D.R.; Gómez-Silván, C.; Pozo, C.; Andersen, G.L.; González-Lopez, J.; Aranda, E. Penicillium oxalicum XD-3.1 removes pharmaceutical compounds from hospital wastewater and outcompetes native bacterial and fungal communities in fluidised batch bioreactors. Int. Biodeterior. Biodegrad. 2021, 158, 105179. [CrossRef]

17. Ogwugwa, V.H.; Oyetibo, G.O.; Amund, O.O. Taxonomic profiling of bacteria and fungi in freshwater sewer receiving hospital wastewater. Environ. Res. 2021, 192, 110319. [CrossRef]

18. Dovlatabadi, A.; Estiri, E.H.; Najafi, M.L.; Ghorbani, A.; Rezaei, H.; Behmanesh, M.; Momeni, E.; Gholizadeh, A.; Cristaldi, A.; Mancini, G.; et al. Bioaccumulation and health risk assessment of exposure to potentially toxic elements by consuming agricultural products irrigated with wastewater effluents. Environ. Res. 2022, 205, 112479. [CrossRef]

19. Huang, L.; Cheng, S.; Chen, G. Bioelectrochemical systems for efficient recalcitrant wastes treatment. J. Chem. Technol. Biotechnol. 2010, 86, 481-491. [CrossRef] 
20. Zhang, M.; Cui, L.; Sheng, L.; Wang, Y. Distribution and enrichment of heavy metals among sediments, water body and plants in Hengshuihu Wetland of Northern China. Ecol. Eng. 2009, 35, 563-569. [CrossRef]

21. Sohail, T.; Lin, M.; Lizhi, X.; Rizwanullah, L.; Nasrullah, M.; Xiuyuan, M.; Manzoor, Y.Z.; Elis, R.J. Farmers' awareness about impacts of reusing wastewater, risk perception and adaptation to climate change in Faisalabad District, Pakistan. Pol. J. Environ. Stud. 2021, 30, 4663-4675. [CrossRef]

22. Oliveira, T.S. Environmental contamination from health-care facilities. In Health Care and Environmental Contamination; Springer: Berlin/Heidelberg, Germany, 2018; pp. 7-19. [CrossRef]

23. Akin, B.S. Contaminant properties of hospital clinical laboratory wastewater: A physiochemical and microbiological assessment. J. Environ. Prot. 2016, 7, 635-642. [CrossRef]

24. Al Aukidy, M.; Verlicchi, P.; Voulvoulis, N. A framework for the assessment of the environmental risk posed by pharmaceuticals originating from hospital effluents. Sci. Total Environ. 2014, 493, 54-64. [CrossRef]

25. Rand-Weaver, M.; Margiotta-Casaluci, L.; Patel, A.; Panter, G.H.; Owen, S.F.; Sumpter, J.P. The read-across hypothesis and environmental risk assessment of pharmaceuticals. Environ. Sci. Technol. 2013, 47, 11384-11395. [CrossRef]

26. Malchi, T.; Maor, Y.; Tadmor, G.; Shenker, M.; Chefetz, B. Irrigation of root vegetables with treated wastewater: Evaluating uptake of pharmaceuticals and the associated human health risks. Environ. Sci. Technol. 2014, 48, 9325-9333. [CrossRef]

27. Pan, M.; Wong, C.K.C.; Chu, L.M. Distribution of antibiotics in wastewater-irrigated soils and their accumulation in vegetable crops in the Pearl River delta, Southern China. J. Agric. Food Chem. 2014, 62, 11062-11069. [CrossRef]

28. Prosser, R.S.; Sibley, P.K. Human health risk assessment of pharmaceuticals and personal care products in plant tissue due to biosolids and manure amendments, and wastewater irrigation. Environ. Int. 2015, 75, 223-233. [CrossRef]

29. Christou, A.; Agüera, A.; Bayona, J.M.; Cytryn, E.; Fotopoulos, V.; Lambropoulou, D.; Manaia, C.M.; Michael, C.; Revitt, M.; Schröder, P. The potential implications of reclaimed wastewater reuse for irrigation on the agricultural environment: The knowns and unknowns of the fate of antibiotics and antibiotic resistant bacteria and resistance genes-A review. Water Res. 2017, 123, 448-467. [CrossRef]

30. Khan, M.T.; Shah, I.A.; Ihsanullah, I.; Naushad, M.; Ali, S.; Shah, S.H.A.; Mohammad, A. Hospital wastewater as a source of environmental contamination: An overview of management practices, environmental risks, and treatment processes. J. Water Process. Eng. 2021, 41, 101990. [CrossRef]

31. Rasheed, T.; Bilal, M.; Nabeel, F.; Adeel, M.; Iqbal, H.M.N. Environmentally-related contaminants of high concern: Potential sources and analytical modalities for detection, quantification, and treatment. Environ. Int. 2019, 122, 52-66. [CrossRef] [PubMed]

32. Gomes, I.B.; Simões, L.C.; Simões, M. The effects of emerging environmental contaminants on Stenotrophomonas maltophilia isolated from drinking water in planktonic and sessile states. Sci. Total Environ. 2018, 643, 1348-1356. [CrossRef] [PubMed]

33. Raja, S.; Cheema, H.M.N.; Babar, S.; Khan, A.A.; Murtaza, G.; Aslam, U. Socio-economic background of wastewater irrigation and bioaccumulation of heavy metals in crops and vegetables. Agric. Water Manag. 2015, 158, 26-34. [CrossRef]

34. Hassan, N.; Mahmood, Q.; Waseem, A.; Irshad, M.; Faridullah; Pervez, A. Assessment of heavy metals in wheat plants irrigated with contaminated wastewater. Pol. J. Environ. Stud. 2013, 22, 115-123.

35. Murtaza, G.; Ghafoor, A.; Qadir, M.; Owens, G.; Aziz, M.A.; Zia, M.H.; Saifullah. Disposal and Use of Sewage on Agricultural Lands in Pakistan: A Review. Pedosphere 2010, 20, 23-34. [CrossRef]

36. Fisher, M.M.; Eugster, E.A. What is in our environment that effects puberty? Reprod. Toxicol. 2014, 44, 7-14. [CrossRef] [PubMed]

37. Rashid, A.; Mirza, S.A.; Keating, C.; Ali, S.; Campos, L.C. Hospital wastewater treated with a novel bacterial consortium (Alcaligenes faecalis and Bacillus paramycoides spp.) for phytotoxicity reduction in Berseem clover and tomato crops. Water Sci. Technol. 2021, 83, 1764-1780. [CrossRef]

38. Rashid, A.; Mirza, S.A.; Keating, C.; Ali, S.; Campos, L.C. Indigenous Bacillus paramycoides spp. and Alcaligenes faecalis: Sustainable solution for bioremediation of hospital wastewater. Environ. Technol. 2020, 1-14. [CrossRef]

39. Starkl, M.; Anthony, J.; Aymerich, E.; Brunner, N.; Chubilleau, C.; Das, S.; Ghangrekar, M.M.; Kazmi, A.A.; Philip, L.; Singh, A Interpreting best available technologies more flexibly: A policy perspective for municipal wastewater management in India and other developing countries. Environ. Impact Assess. Rev. 2018, 71, 132-141. [CrossRef]

40. Zhao, L.; Dai, T.; Qiao, Z.; Sun, P.; Hao, J.; Yang, Y. Application of artificial intelligence to wastewater treatment: A bibliometric analysis and systematic review of technology, economy, management, and wastewater reuse. Process. Saf. Environ. Prot. 2020, 133, 169-182. [CrossRef]

41. Granata, F.; Papirio, S.; Esposito, G.; Gargano, R.; De Marinis, G. Machine learning algorithms for the forecasting of wastewater quality indicators. Water 2017, 9, 105. [CrossRef]

42. Mazhar, S.; Ditta, A.; Bulgariu, L.; Ahmad, I.; Ahmed, M.; Nadiri, A. Sequential treatment of paper and pulp industrial wastewater: Prediction of water quality parameters by Mamdani Fuzzy Logic model and phytotoxicity assessment. Chemosphere 2019, 227, 256-268. [CrossRef] [PubMed]

43. Wang, Z.; Man, Y.; Hu, Y.; Li, J.; Hong, M.; Cui, P. A deep learning based dynamic COD prediction model for urban sewage. Environ. Sci. Water Res. Technol. 2019, 5, 2210-2218. [CrossRef]

44. Zhu, X.; Wang, X.; Ok, Y.S. The application of machine learning methods for prediction of metal sorption onto biochars. J. Hazard. Mater. 2019, 378, 120727. [CrossRef] [PubMed] 
45. Benjamini, Y.; Hochberg, Y. Controlling the false discovery rate: A practical and powerful approach to multiple testing. J. R. Stat. Soc. Ser. B (Methodol.) 1995, 57, 289-300. Available online: http://www.jstor.org/stable/2346101 (accessed on 24 June 2021). [CrossRef]

46. Breiman, L. Random forests. Mach. Learn. 2001, 45, 5-32. [CrossRef]

47. Wrap, T.C.A. Public Available Specification 100-Specification for Composted Material. Annex D: Method Assess Contam. Weed Propagules Phytotoxins Compost. Mater. The Waste and Resources Action Program (WRAP). 2002. Available online: https://scholar. google.com/scholar?q=Public\%20available $\% 20$ specification $\% 20100 \% 20 \% 20$ specification $\% 20$ for $\% 20$ composted $\% 20$ material (accessed on 26 September 2021).

48. Hoekstra, N.J.; Bosker, T.; Lantinga, E.A. Effects of cattle dung from farms with different feeding strategies on germination and initial root growth of cress (Lepidium sativum L.). Agric. Ecosyst. Environ. 2002, 93, 189-196. [CrossRef]

49. Neves, L.C.; de Souza, J.B.; Vidal, C.M.D.; Herbert, L.T.; de Souza, K.V.; Martins, K.G.; Young, B.J. Phytotoxicity indexes and removal of color, COD, phenols and ISA from pulp and paper mill wastewater post-treated by UV/H2O2 and photo-Fenton. Ecotoxicol. Environ. Saf. 2020, 202, 110939. [CrossRef]

50. Tiquia, S.M.; Tam, N.F.Y.; Hodgkiss, I.J. Effects of composting on phytotoxicity of spent pig-manure sawdust litter. Environ. Pollut. 1996, 93, 249-256. [CrossRef]

51. Bagur-González, M.G.; Estepa-Molina, C.; Martín-Peinado, F. Toxicity assessment using Lactuca sativa L. bioassay of the metal(loid)s As, $\mathrm{Cu}, \mathrm{Mn}, \mathrm{Pb}$ and $\mathrm{Zn}$ in soluble-in-water saturated soil extracts from an abandoned mining site. J. Soils Sediments 2011, 11, 281-289. [CrossRef]

52. Rusan, M.J.; Albalasmh, A.A.; Zuraiqi, S.; Bashabsheh, M. Evaluation of phytotoxicity effect of olive mill wastewater treated by different technologies on seed germination of barley (Hordeum vulgare L.). Environ. Sci. Pollut. Res. 2015, 22, 9127-9135. [CrossRef]

53. Welch, M. Corrections: A Critical Approach, 3rd ed.; Routledge: London, UK, 2011. [CrossRef]

54. Wang, D.; Thunéll, S.; Lindberg, U.; Jiang, L.; Trygg, J.; Tysklind, M.; Souihi, N. A machine learning framework to improve effluent quality control in wastewater treatment plants. Sci Total Environ. 2021, 784, 147138. [CrossRef]

55. Arismendy, L.; Cárdenas, C.; Gómez, D.; Maturana, A.; Mejía, R.; Quintero M., C.G. Intelligent System for the Predictive Analysis of an Industrial Wastewater Treatment Process. Sustainability 2020, 12, 6348. [CrossRef]

56. Qin, X.; Gao, F.; Chen, G. Wastewater quality monitoring system using sensor fusion and machine learning techniques. Water Res. 2012, 46, 1133-1144. [CrossRef]

57. Li, L.; Rong, S.; Wang, R.; Yu, S. Recent advances in artificial intelligence and machine learning for nonlinear relationship analysis and process control in drinking water treatment: A review. Chem. Eng. J. 2021, 405, 126673. [CrossRef]

58. Kermet-Said, H.; Moulai-Mostefa, N. Optimization of Turbidity and COD Removal from Pharmaceutical Wastewater by Electrocoagulation. Isotherm Modeling and Cost Analysis. Pol. J. Environ. Stud. 2015, 24, 1049-1061. [CrossRef]

59. Icke, O.; van Es, D.M.; de Koning, M.F.; Wuister, J.J.G.; Ng, J.; Phua, K.M.; Koh, Y.K.K.; Chan, W.J.; Tao, G. Performance improvement of wastewater treatment processes by application of machine learning. Water Sci. Technol. 2020, 82, 2671-2680. [CrossRef]

60. Ahmed, F.; Arshad, M.; Ditta, A.; Hussain, A.; Naveed, M.; Hasnain, M.; Nazir, Q. Combining textile effluent wastewater with organic fertilizer for improved growth and productivity of wheat and soil health. J. Environ. Agric. Sci. 2016, 8, 14-20.

61. Kopittke, P.M.; Blamey, F.P.C.; Asher, C.J.; Menzies, N.W. Trace metal phytotoxicity in solution culture: A review. J. Exp. Bot. 2010, 61,945-954. [CrossRef]

62. Rana, S.; Kumar, K. Study of phytotoxic effect of textile wastewater on seed germination and seedling growth of T. aestivum. Int. J. Biosci. Technol. 2017, 10, 58-66.

63. Raklami, A.; Oubane, M.; Meddich, A.; Hafidi, M.; Marchner, B.; Heinze, S.; Oufdou, K. Phytotoxicity and genotoxicity as a new approach to assess heavy metals effect on Medicago sativa L.: Role of metallo-resistant rhizobacteria. Environ. Technol. Innov. 2021, 24, 101833. [CrossRef]

64. Divya, L.; George, J.; Midhun, G.; Magesh, S.B.; Suriyanarayanan, S. Impacts of treated sewage effluent on seed germination and vigour index of monocots and dicot seeds. Russ. Agric. Sci. 2015, 41, 252-257. [CrossRef]

65. Aviani, I.; Raviv, M.; Hadar, Y.; Saad, I.; Laor, Y. Original and residual phytotoxicity of olive mill wastewater revealed by fractionations before and after incubation with Pleurotus ostreatus. J. Agric. Food Chem. 2009, 57, 11254-11260. [CrossRef]

66. Ben-Gal, A.; Borochov-Neori, H.; Yermiyahu, U.; Shani, U. Is osmotic potential a more appropriate property than electrical conductivity for evaluating whole-plant response to salinity? Environ. Exp. Bot. 2009, 65, 232-237. [CrossRef]

67. Christou, A.; Papadavid, G.; Dalias, P.; Fotopoulos, V.; Michael, C.; Bayona, J.M.; Piña, B.; Fatta-Kassinos, D. Ranking of crop plants according to their potential to uptake and accumulate contaminants of emerging concern. Environ. Res. 2019, 170, 422-432 [CrossRef] [PubMed]

68. You, R.; Domínguez, C.; Matamoros, V.; Bayona, J.M.; Diez, S. Chemical characterization and phytotoxicity assessment of peri-urban soils using seed germination and root elongation tests. Environ. Sci. Pollut. Res. 2019, 26, 34401-34411. [CrossRef] [PubMed]

69. Fargasova, A. Phytotoxicity of chromium and nickel. Ecol. Chem. Eng. 2008, 15, 335-348. Available online: http://tchie.uni.opole. pl/freeECE/S_15_3/Fargasova_15(S3).pdf (accessed on 25 June 2021).

70. Fiansconaro, M.L.; Antolin, M.C.; Lovato, M.E.; Gervasio, S.; Martin, C.A. Study of fat compost from dairy industry wastewater as a new substrate for pepper (Capsicum annuum L.) crop. Sci. Hortic. 2015, 193, 359-366. [CrossRef] 
71. Díaz-Pérez, M.; Camacho-Ferre, F. Effect of composts in substrates on the growth of tomato transplants. Hort. Technol. 2010, 20, 361-367. [CrossRef]

72. Pérez-Murcia, M.D.; Moral, R.; Moreno-Caselles, J.; Perez-Espinosa, A.; Paredes, C. Use of composted sewage sludge in growth media for broccoli. Bioresoure Technol. 2006, 97, 123-130. [CrossRef]

73. García-Gómez, A.; Bernal, M.P.; Roig, A. Growth of ornamental plants in two composts prepared from agroindustrialwastes. Bioresoure Technol. 2002, 83, 81-87. [CrossRef]

74. Hong, C.L.; Jia, Y.B.; Yang, X.E.; He, Z.L.; Stofella, P.J. Assessing lead thresholds for phytotoxicity and potential dietary toxicity in selected vegetable crops. Bull. Environ. Contam. Toxicol. 2008, 80, 356-361. [CrossRef]

75. Casa, R.; D'Annibale, A.; Pieruccetti, F.; Stazi, S.R.; Sermanni, G.G.; Cascio, B.L. Reduction of the phenolic components in olivemill wastewater by an enzymatic treatment and its impact on durum wheat (Triticum durum Desf.) germinability. Chemosphere 2003, 50, 959-966. [CrossRef]

76. Mukhtar, A.; Manzoor, M.; Gul, I.; Zafar, R.; Jamil, H.I.; Niazi, A.K.; Ali, M.A.; Park, T.J.; Arshad, M. Phytotoxicity of different antibiotics to rice and stress alleviation upon application of organic amendments. Chemosphere 2020, 258, 127353. [CrossRef]

77. Rivera, E.B.; Milla, O.V.; Huang, W.; Ho, Y.; Chiu, J.; Chang, H. Rice germination as a bioassay to test the phytotoxicity of MSWI bottom ash recycling wastewater. J. Hazard. Toxicradioact. Waste 2013, 17, 140-145. [CrossRef]

78. Noel, S.D.; Rajan, M.R. Impact of dyeing industry effluent on ground water quality by water quality index and correlation analysis Res. Biotechnol. 2015, 6, 47-53. Available online: http:/ / www.researchinbiotechnology.com/ (accessed on 28 November 2021).

79. Amin, H.; Arain, B.; Amin, F.; Surhio, M. Phytotoxicity of chromium on germination, growth and biochemical attributes of Hibiscus esculentus L. Am. J. Plant. Sci. 2013, 4, 2431-2439. [CrossRef]

80. Garg, V.K.; Kaushik, P. Influence of textile mill wastewater irrigation on the growth of Sorghum cultivars. Appl. Ecol. Environ. Res. 2007, 6, 1-12. [CrossRef]

81. Selim, S.M.; Zayed, M.S.; Atta, H.M. Evaluation of phytotoxicity of compost during composting process. Nat. Sci. 2012, 10, 69-77.

82. Zwolak, A.; Sarzyńska, M.; Szpyrka, E.; Stawarczyk, K. Sources of soil pollution by heavy metals and their accumulation in vegetables: A review. Water Air Soil Pollut. 2019, 230, 164. [CrossRef]

83. Ceschin, S.; Bellini, A.; Scalici, M. Aquatic plants and ecotoxicological assessment in freshwater ecosystems: A review. Environ. Sci Pollut Res. 2021, 28, 4975-4988. [CrossRef] [PubMed]

84. Qiao, K.; Wang, F.; Liang, S.; Wang, H.; Hu, Z.; Chai, T. Improved Cd, Zn and Mn tolerance and reduced Cd accumulation in grains with wheat-based cell number regulator TaCNR2. Sci. Rep. 2019, 9, 870. [CrossRef]

85. Arif, N.; Sharma, N.C.; Yadav, V.; Ramawat, N.; Dubey, N.K.; Tripathi, D.K.; Chauhan, D.K.; Sahi, S. Understanding heavy metal stress in a rice crop: Toxicity, tolerance mechanisms, and amelioration strategies. J. Plant. Biol. 2019, 62, 239-253. [CrossRef]

86. Chow, Y.N.; Lee, L.K.; Foo, K.Y. Scientific rationale of hospital discharge as a sustainable source of irrigation water: Detection, phytological assessment and toxicity verification. Process. Saf. Environ. Prot. 2021, 148, 834-845. [CrossRef]

87. Christou, A.; Michael, C.; Fatta-Kassinos, D.; Fotopoulos, V. Can the pharmaceutically active compounds released in agroecosystems be considered as emerging plant stressors? Environ. Int. 2018, 114, 360-364. [CrossRef]

88. Ma, Y.; Liu, Y. Turning food waste to energy and resources towards a great environmental and economic sustainability: An innovative integrated biological approach. Biotechnol. Adv. 2019, 37, 107414. [CrossRef]

89. Ji, B. Towards environment-sustainable wastewater treatment and reclamation by the non-aerated microalgal-bacterial granular sludge process: Recent advances and future directions. Sci. Total Environ. 2022, 806, 150707. [CrossRef] [PubMed] 